\title{
Oxidative Stress and Antioxidant Status in Patients of acute Myocardial Infarction before and after Regular Treatment
}

TAHMINA BASHAR, NARGIS AKHTER

\author{
Department of Pharmacology, Bangabandhu Sheikh Mujib Medical University (BSMMU), Dhaka \\ Address of Correspondence: Dr. Tahmina Bashar, Research Assistant, Department of Pharmacology BSMMU, \\ Email: tahminabashar6@gmail.com
}

\begin{abstract}
:
In acute myocardial infarction (AMI), generation of free radicals contribute to its pathogenesis. We evaluated the extent of oxidative stress and its amelioration in AMI patients after regular treatment and assessed its association with risk factors like dyslipidemia and diabetes mellitus (DM). Plasma MDA level increased $(p<0.001)$ and erythrocyte GSH and plasma vitamin E levels decreased $(p<0.001)$ in AMI patients. On the $5^{\text {th }}$ day of regular treatment MDA level reduced $(p<0.001)$ and erythrocyte GSH and vitamin $E$ levels increased $(p<0.001)$. The rise in MDA and fall in vitamin $E$ levels were significant $(p<0.001)$ in patients with both dyslipidemia and DM in comparison to patients without dyslipidemia or DM. It is concluded that an imbalance exists between oxidant and antioxidant molecules in AMI patients which shifts towards oxidative side and treatment restores this balance. There may be some association between oxidative stress in AMI and risk factors like dyslipidemia and diabetes mellitus.
\end{abstract}

Keywords: Oxidative stress, Malondialdehyde, Reduced glutathione, Vitamin E, Cardiovascular risk factors.

\section{Introduction:}

Acute myocardial infarction is one of the leading causes of mortality and morbidity in the world. AMI generally occurs following an abrupt impediment of coronary blood flow after a thrombotic occlusion of a coronary artery as a result of atherosclerosis. ${ }^{1}$ This vascular injury is facilitated by some factors hypertension, dyslipidemia, diabetes etc. ${ }^{2}$ Besides these factors, reactive oxygen species (ROS) may play an important role in the pathogenesis of AMI. ${ }^{(3)}$ Myocardial ischemia, a decrease in the blood supply to the heart leads to reperfusion in the myocardium, where interaction between molecular oxygen and the reduced respiratory chain causes formation of ROS. ${ }^{4}$ These ROS may have several different deleterious effects on heart. The effect of increased oxidative stress leads to the oxidative damage of proteins, lipids, DNA and enzymes of myocardial cells that involved in energy production. These factors contribute to myocardial cell damage, extensive necrosis and cellular oedema. ${ }^{5}$ In addition, increasing ROS leads to lipid peroxidation of membranes and loss of its integrity, resulting in necrosis and cell death. ${ }^{6}$ Lipid peroxidation leads to generation of a variety of aldehydic products of which malandialdehyde (MDA), a stable end product, is frequently used as a marker of ROS production. ${ }^{7}$ The deleterious effect of ROS is balanced by the antioxidant action of non-enzymatic as well as enzymatic antioxidants. Vitamins and reduced glutathione (GSH) are important non-enzymatic antioxidant defenses. ${ }^{8}$ Vitamin E has a strong antioxidant capacity which plays an important role in maintaining cell membrane integrity by interacting with membrane phospholipids and thereby limiting lipid peroxidation by ROS. ${ }^{9}$ On the other hand, GSH, the most important endogenous antioxidant, maintains $\mathrm{SH}$ groups of proteins in reduced state that detoxifies ROS and prevents ROS induced cellular damage. ${ }^{(10)}$ There is evidence that antioxidants can protect against free radical defense and may thereby inhibit thrombosis and myocardial damage during AMI. In AMI oxidative stress is developed because of excessive production of ROS and outstripping endogenous antioxidant mechanism so antioxidant status is the critical tool for assessing redox status. ${ }^{11}$

AMI is a multifactorial disease. Recent studies have demonstrated an association between increased oxidative stress and diabetes, hypertension, smoking etc. which are well known risk factors for atherosclerosis. ${ }^{12}$ Lipid profile has been found to be deranged in AMI patients. Increased oxidative stress leads to generation of ROS, causes modification of LDL that initiates further generation of ROS. ${ }^{13}$ However in diabetic patients, hyperglycemia increases the production of ROS by auto-oxidation of lipoproteins, proteins and glucose and reduces the availability of nitric oxide (NO) ${ }^{14}$ which maintains antioxidative capacity of endothelial cells. ${ }^{(15)}$ Therefore the present study is designed to evaluate the extent of oxidative stress in AMI and to assess antioxidant protection against ROS in AMI patients after regular treatment. In addition the study will also evaluate an 
association between oxidative stress and risk factors for atherosclerosis like dyslipidemia and diabetes mellitus.

\section{Materials and Methods:}

This prospective type of observational study was conducted in the department of Pharmacology, Bangabandhu Sheikh Mujib Medical University (BSMMU) and National Institute of Cardiovascular Diseases (NICVD), Dhaka from July 2010 to May, 2011.

\section{Study design:}

The study was consisted of 72 patients (52 males and 16 females) of mean age group $53.15 \pm 7.59$ years with the diagnosis of AMI admitted into Coronary Care Unit (CCU) of NICVD. Control group consisted of 18 healthy subjects, recruited from Matuail Health Complex attending for health check up. The whole population was grouped as follows:

\begin{tabular}{|c|c|}
\hline GroupI or control & - 18 healthy subjects \\
\hline GroupII or study & $\begin{array}{l}72 \text { AMI patients } \\
\text { Sub-divided as follows: }\end{array}$ \\
\hline GroupIIa & $\begin{array}{l}\text { - } 18 \text { AMI patients without diabetes } \\
\text { mellitus or dyslipidemia }\end{array}$ \\
\hline GroupIIb & - 18 AMI patients with dyslipidemia \\
\hline GroupIIc & $\begin{array}{l}\text { - } 18 \text { AMI patients with diabetes } \\
\text { mellitus }\end{array}$ \\
\hline GroupIId & $\begin{array}{l}\text { - } 18 \text { AMI patients with both } \\
\text { diabetes mellitus and dyslipidemia }\end{array}$ \\
\hline
\end{tabular}

Diagnostic criteria of patients: The diagnosis of AMI was based on a history of prolonged ischemic chest pain, characteristic ECG changes (ST elevation of $2 \mathrm{~mm}$ or more in at least 2 contagious leads) and elevated creatine kinase isoenzyme $\mathrm{MB}$ (CK-MB) and troponin T within 8 hours after the onset of pain. ${ }^{16}$ All the patients received conventional therapy for AMI which included Inj. streptokinase, Inj. morphine, Inj. prochlorperazine, Tab. clopidogrel, Tab. atrovastatin. Patients who already received antihypertensive, antidiabetic and lipid lowering agents should be continued according to needs. General patients characteristics are shown in table-l. Hypertension was defined as a diastolic blood pressure $\geq 90 \mathrm{~mm}$ of $\mathrm{Hg}$ and systolic blood pressure $\geq 140 \mathrm{~mm}$ of $\mathrm{Hg}$ or self reported use of antihypertensive drugs. The subjects who had total cholesterol level of $<200 \mathrm{mg} / \mathrm{dL}$, triglycerides $<150 \mathrm{mg}$ / $\mathrm{dL}, \mathrm{LDL}-\mathrm{C}<160 \mathrm{mg} / \mathrm{dL}$ and HDL-C > 35 mg/dL were defined as normolipidemic patients, patients treated with insulin or oral hypoglycemic agents were considered as diabetic. The control group consisted of 18 healthy individuals aged $54.13 \pm 6.74$ years, males or females; who presented normal blood pressure, were free from diabetes or chronic ailments. Patients with impaired renal or liver functions were excluded from the study. Prior to study, written consent was taken from the patients with AMI and normal subjects.

The protocol was approved by the Ethical Committee of the Bangabandhu Sheikh Mujib Medical University, Dhaka, Bangladesh.

Blood collection and erythrocyte lysate preparation: With all aseptic precautions $5 \mathrm{ml}$ blood was collected in $\mathrm{K}_{3}$ EDTA containing tube. Plasma was separated by centrifugation at $1370 \times \mathrm{g}$ for 10 minutes. The packed cells were washed thrice with cold $0.9 \%$ saline by centrifugation. They were suspended in five volumes of deionized water at $4^{\circ} \mathrm{C}$ for 24 hours to lyse RBCs then centrifuged them to collect RBCs lysate. Finally all samples were stored at $-10^{\circ} \mathrm{C}$. Blood samples of AMI patients were collected once on admission before starting treatment and on the 5th day of treatment and in control once after overnight fasting.

Lipid peroxidation was estimated by measurement of thiobarbituric acid reactive substances (TBARS) in plasma by the method of Yagi. ${ }^{17}$

Reduced glutathione (GSH) in RBC was determined by the method of Ellman. ${ }^{18}$

Plasma vitamin E was measured by the method of Baker et al. ${ }^{19}$

Plasma glucose and lipid profiles (total cholesterol, triglycerides, LDL-C, HDL-C) were analyzed enzymatically using commercial kits.

All chemicals and enzymatical kits were purchased from Sigma and Human, Germany.

Statistical analysis: Statistical analysis was done by SPSS software (SPSS 15.0). The quantitative variables were expressed as mean \pm SD. ANOVA followed by Bonferroni $t$ test was done to measure level of significance for statistical analysis. $\mathrm{P}$ value $<0.05$ was considered to indicate statistical significance.

\section{Results:}

The demographic characteristics of control and all AMI patients are shown in Table I. All females were nonsmoker while males were either smoker or nonsmoker or ex-smoker. Incidence of hypertension was more common in AMI patients with both DM and dyslipidemia.

Blood glucose level of AMI patients with DM or dyslipidemia or with both DM and dyslipidemia was significantly high $(\mathrm{p}<0.001)$ as compared to control (Table II). Compared with controls, the level was also higher 
Table-I

Demographic characteristics of AMI patients and control

\begin{tabular}{|c|c|c|c|c|c|}
\hline \multirow[t]{3}{*}{ Parameters } & \multirow[t]{2}{*}{ Control } & \multicolumn{4}{|c|}{ AMI Patients(72) } \\
\hline & & $\begin{array}{l}\text { AMI without } \\
\text { DM or } \\
\text { Dyslipidemia }\end{array}$ & $\begin{array}{c}\text { AMI with } \\
\text { Dyslipidemia }\end{array}$ & $\begin{array}{l}\text { AMI with } \\
\text { DM }\end{array}$ & $\begin{array}{l}\text { AMI with } \\
\text { both DM and } \\
\text { Dyslipidemia }\end{array}$ \\
\hline & $\begin{array}{l}\text { Group I } \\
(\mathrm{n}=18)\end{array}$ & $\begin{array}{l}\text { Group IIa } \\
(\mathrm{n}=18)\end{array}$ & $\begin{array}{c}\text { Group IIb } \\
(\mathrm{n}=18)\end{array}$ & $\begin{array}{c}\text { Group IIc } \\
(\mathrm{n}=18)\end{array}$ & $\begin{array}{l}\text { Group IId } \\
(\mathrm{n}=18)\end{array}$ \\
\hline Age $($ mean $\pm S D)$ in years & $54.13 \pm 6.74$ & $45.20 \pm 6.52$ & $52.27 \pm 8.87$ & $58.80 \pm 6.88$ & $56.33 \pm 9.52$ \\
\hline Sex: Male/Female & $71 \% / 29 \%$ & $71 \% / 29 \%$ & $71 \% / 29 \%$ & $71 \% / 29 \%$ & $71 \% / 29 \%$ \\
\hline \multicolumn{6}{|l|}{ Risk factors: } \\
\hline Hypertension & - & $8(44 \%)$ & $11(61 \%)$ & $9(50 \%)$ & $15(83 \%)$ \\
\hline \multirow[t]{3}{*}{ Smoking } & Smoker-7 (39\%) & $-14(78 \%)$ & $-10(56 \%)$ & $-7(39 \%)$ & $-5(28 \%)$ \\
\hline & Ex. Smoker-1(6\%) & $-0(0 \%)$ & $-4(22 \%)$ & $-4(22 \%)$ & $-5(28 \%)$ \\
\hline & Non Smoker - 1 (55\%) & $-4(22 \%)$ & $-4(22 \%)$ & $-7(39 \%)$ & $-8(44 \%)$ \\
\hline $\begin{array}{l}\mathrm{H} / \mathrm{O} \text { CAD in the } \\
\text { family }\end{array}$ & - & $4(22 \%)$ & - & $2(11 \%)$ & $3(17 \%)$ \\
\hline
\end{tabular}

Continuous variables are presented as mean \pm SD and other variables are shown as percentage of patients

Table-II

Blood glucose level and plasma lipid profile in AMI patients and control

\begin{tabular}{|c|c|c|c|c|c|}
\hline \multirow[t]{3}{*}{ Parameters } & \multirow[t]{2}{*}{ Control } & \multicolumn{4}{|c|}{ AMI Patients(72) } \\
\hline & & $\begin{array}{l}\text { AMI without } \\
\text { DM or } \\
\text { Dyslipidemia }\end{array}$ & $\begin{array}{c}\text { AMI with } \\
\text { Dyslipidemia }\end{array}$ & $\begin{array}{c}\text { AMI with } \\
\text { DM }\end{array}$ & $\begin{array}{c}\text { AMI with } \\
\text { both DM and } \\
\text { Dyslipidemia }\end{array}$ \\
\hline & $\begin{array}{l}\text { Group I } \\
(n=18)\end{array}$ & $\begin{array}{l}\text { Group IIa } \\
(n=18)\end{array}$ & $\begin{array}{l}\text { Group IIb } \\
(n=18)\end{array}$ & $\begin{array}{c}\text { Group IIc } \\
(n=18)\end{array}$ & $\begin{array}{l}\text { Group IId } \\
(n=18)\end{array}$ \\
\hline Blood Glucose (70-110 mg/dl) & $89 \pm 8.40$ & $97 \pm 2.82^{* *}$ & $104 \pm 3.79^{* * *}$ & $132 \pm 9.11^{* * *}$ & $140 \pm 8.19^{* * *}$ \\
\hline Total Cholesterol(150-200 mg/dl) & $162 \pm 11.23$ & $172 \pm 13.46^{*}$ & $221 \pm 17.41^{* * *}$ & $179 \pm 18.42^{* *}$ & $238 \pm 19.17^{* * *}$ \\
\hline Triglyceride(50-150 mg/dl) & $137 \pm 21.23$ & $143 \pm 23.10^{\mathrm{NS}}$ & $177 \pm 21.26^{* * *}$ & $141 \pm 13.43^{\mathrm{NS}}$ & $174 \pm 11.03^{* * *}$ \\
\hline LDL-C(100-160 mg/dl) & $92 \pm 9.11$ & $100 \pm 5.07^{* *}$ & $155 \pm 8.32^{* * *}$ & $110 \pm 9.72^{* * *}$ & $173 \pm 12.08^{* * *}$ \\
\hline HDL-C(40-55 mg/dl) & $43 \pm 5.09$ & $43 \pm 4.13^{\mathrm{NS}}$ & $31 \pm 4.32^{* * *}$ & $41 \pm 5.19^{\mathrm{NS}}$ & $30 \pm 6.01^{* * *}$ \\
\hline
\end{tabular}

Values were expressed as mean $\pm \mathrm{SD}$;

"Unpaired t test" was done between study groups and control group

Group IIa/ IIb/ IIc/ IId (study groups) compared to Group I (control)

$* * *=$ significant at $\mathrm{p}<0.001 ; * *=$ significant at $\mathrm{p}<0.01 *^{*}=$ significant at $\mathrm{p}<0.05$; ns $=$ not significant at $\mathrm{p}>0.05$

$(\mathrm{p}<0.01)$ in AMI patients without DM or dyslipidemia. Plasma lipids showed a higher concentration $(\mathrm{p}<0.001)$ of total cholesterol (TC), triglyceride (TG) and low density lipoproteins (LDL-C) in patients with dyslipidemia and with both dyslipidemia and DM. LDL-C level was also high $(\mathrm{p}<0.001)$ in AMI with DM. Total cholesterol level was high $(\mathrm{p}<0.05)$ in AMI patients without DM or dyslipidemia as compared to control. Total cholesterol level was significantly higher $(\mathrm{p}<0.01)$ in AMI patients with DM. The level of LDL-C was also higher $(p<0.01)$ in AMI patients without dyslipidemia or DM as compared to controls. The difference in TG concentration in AMI patients without DM or dyslipidemia or with DM as compared to controls was not significant. On the other hand the level of HDL-C was lower $(\mathrm{p}<0.01)$ in patients with dyslipidemia and with both DM and dyslipidemia when compared to healthy control subjects. The change in HDL-C concentration was not significant in patients without DM or dyslipidemia and in patients with DM when compared to controls.

Table III illustrates the level of lipid peroxidation and antioxidant status in different groups of AMI patients and 
control subjects. Lipid peroxidative marker, MDA, was significantly higher $(\mathrm{p}<0.001)$ in all groups of AMI patients as compared to control. The activity of erythrocyte antioxidant GSH and plasma concentration of vitamin $\mathrm{E}$ levels declined $(\mathrm{p}<0.001)$ in all group of AMI patients when compared to normal subjects. Significant difference $(\mathrm{p}<0.001)$ in plasma MDA level was observed between group IId versus group IIa. However no significant change ( $>0.05$ ) in MDA, erythrocyte GSH and vitamin E level was observed in group IIb as compared to group IIa. MDA level increased significantly $(\mathrm{p}<0.001)$ in group IIc versus group IIa. Significant increase in MDA level was observed when group IId was compared with group IIa $(\mathrm{p}<0.001)$. Significant reduction in vitamin E level was found in group IIc versus group IIa $(\mathrm{p}<0.05)$ and group IId versus IIa $(\mathrm{p}<0.01)$.
Table IV illustrates the level of lipid peroxidation and antioxidant status before starting regular treatment and on the $5^{\text {th }}$ day of treatment in all AMI patients and control subjects. Before starting regular treatment plasma MDA level was significantly higher $(\mathrm{p}<0.001)$ and erythrocyte GSH and plasma vitamin E levels were significantly low $(p<0.001)$ in AMI patients when compared to controls. After regular treatment, on the $5^{\text {th }}$ day, plasma concentration of MDA reduced significantly $\left(p^{<0.001)}\right.$ in AMI patients. However, MDA level did not return to the normal value and its difference from control value was significant $(p<0.05)$. On the $5^{\text {th }}$ day of regular treatment non-enzymatic markers of antioxidants, erythrocyte GSH and plasma vitamin E, levels increased significantly ( $\mathrm{p}<0.001)$ in AMI patients as compared to patients before starting regular treatment, but the rise was not upto the control level.

Table-III

Plasma MDA, plasma vitamin E and erythrocyte GSH levels in AMI patients and control

\begin{tabular}{|c|c|c|c|c|c|}
\hline \multirow[t]{2}{*}{ Parameters } & \multirow[t]{2}{*}{ Control } & \multirow[b]{2}{*}{$\begin{array}{l}\text { AMI without } \\
\text { DM or } \\
\text { Dyslipidemia } \\
\text { Group IIa } \\
(n=18)\end{array}$} & \multicolumn{2}{|c|}{ AMI Patients(72) } & \multirow[b]{2}{*}{$\begin{array}{l}\text { AMI with } \\
\text { both DM and } \\
\text { Dyslipidemia } \\
\text { Group IId } \\
(n=18)\end{array}$} \\
\hline & & & $\begin{array}{c}\text { AMI with } \\
\text { Dyslipidemia } \\
\text { Group IIb } \\
(n=18)\end{array}$ & $\begin{array}{l}\text { Group IIc } \\
(n=18)\end{array}$ & \\
\hline Plasma MDA ( $\mu \mathrm{mol} / \mathrm{l})$ & $2.51 \pm 0.42$ & $3.79 \pm 0.96^{\mathrm{a}^{* * *}}$ & $4.47 \pm 0.99^{a^{* * *} \text { bns }}$ & $4.94 \pm 0.79^{a^{* * *} c^{* * *}}$ & $5.85 \pm 0.79^{a^{* * *}} d^{* * *}$ \\
\hline Plasma vitamin E (mg/l) & $8.26 \pm 0.65$ & $4.89 \pm 0.78^{\mathrm{a}^{* * *}}$ & $5.38 \pm 0.90^{\mathrm{a}^{* * *}}$ bns & $5.63 \pm 0.64^{\mathrm{a}^{* * * *} \mathrm{c}^{*}}$ & $5.83 \pm 0.78^{a^{* * *} d^{* *}}$ \\
\hline Erythrocyte GSH (mg/gm of Hb) & $1.31 \pm 0.11$ & $0.91 \pm 0.09^{\mathrm{a}^{* * *}}$ & $0.93 \pm 0.07^{\mathrm{a}^{* * *} \text { bns }}$ & $0.92 \pm 0.05^{\mathrm{a}^{* * *} \mathrm{cns}}$ & $0.96 \pm 0.04^{\mathrm{a}^{* * *} \mathrm{dns}}$ \\
\hline
\end{tabular}

Values were expressed as mean $\pm \mathrm{SD}$;

ANOVA followed by Bonferroni t test was done to measure level of significance

a Group IIa/ IIb/ IIc/ IId (study groups) as compared to Group I (control)

b Group IIb as compared to Group IIa

c Group IIc as compared to Group IIa

d Group IId as compared to Group IIa

$* * *=$ significant at $\mathrm{p}<0.001 ; * *=$ significant at $\mathrm{p}<0.01 ; *=$ significant at $\mathrm{p}<0.05$; ns $=$ not significant at $\mathrm{p}>0.05$

Table-IV

Plasma MDA, plasma vitamin E and erythrocyte GSH levels before and after treatment in AMI patients and control

\begin{tabular}{lccc}
\hline Parameters & Control $n=18$ & \multicolumn{2}{c}{ AMI Patients $n=72$} \\
\cline { 3 - 4 } & & Before Treatment & On the 5 ${ }^{\text {th }}$ day of \\
(At baseline) & Treatment \\
\hline Plasma MDA $(\mu \mathrm{mol} / \mathrm{l})$ & $2.51 \pm 0.42$ & $4.76 \pm 2.72^{\mathrm{a}^{* * *}}$ & $2.78 \pm 2.48^{\mathrm{b}^{* * *}}$ \\
Plasma vitamin E $(\mathrm{mg} / \mathrm{l})$ & $8.26 \pm 0.65$ & $5.43 \pm 1.93^{\mathrm{a}^{* * *}}$ & $7.68 \pm 0.91^{\mathrm{b}^{* * *}}$ \\
Erythrocyte GSH $(\mathrm{mg} / \mathrm{gm}$ of $\mathrm{Hb})$ & $1.31 \pm 0.11$ & $0.93 \pm 0.09^{\mathrm{a}^{* * *}}$ & $1.17 \pm 0.29 \mathrm{~b}^{\text {b**}}$ \\
\hline
\end{tabular}

Values were expressed as mean \pm SD

ANOVA followed by Bonferroni t test was done to measure level of significance

a before treatment group compared to control group

b after treatment group compared to before treatment group

$* * *=$ significant at $\mathrm{p}<0.001 ; * *=$ significant at $\mathrm{p}<0.01 ; *=$ significant at $\mathrm{p}<0.05$; ns $=$ not significant at $\mathrm{p}>0.05$ 


\section{Discussion:}

A decrease in blood supply to the heart due to atherosclerosis, thrombosis or coronary artery spasm is known to induce myocardial ischemia. ${ }^{1}$ Reperfusion of ischemic myocardium may restore oxygen supply. However sudden massive increase in oxygen supply causes a burst of oxygen consumption with consequent generation of reactive oxygen species (ROS). Excess production of ROS causes inhibition of antioxidant activity ${ }^{10,20}$, which may cause modification of cellular lipids, proteins and DNA of myocardium, result in severe myocardial damage. ${ }^{5}$ In the present study lipid peroxidation product, MDA was significantly increased $(\mathrm{p}<0.001)$ in AMI patients as compared to control which is indicative of elevated oxidative stress in AMI patients. Our results are consistent with other researchers findings where they showed significant increase in the lipid peroxidation products in blood of AMI patients following an acute event. ${ }^{1,21-22}$ The same result was found by Senthi et al., (23) in patients with cardiogenic shock complicating AMI. Increased lipid peroxidation is thought to be a consequence of oxidative stress which occurs when the dynamic balance between pro-oxidant and antioxidant mechanism is impaired. Lipid peroxidation may alter intrinsic membrane properties due to physicochemical changes of oxidized lipids or cause polymerization of membrane components. ${ }^{24}$ The increased level of MDA suggests that lipid damage observed in our study may be a result of the AMI pathology itself.

Antioxidants constitute the foremost defense system that limit the toxicity associated with free radicals. A reason for increased lipid peroxidation of patients with AMI may be a poor enzymatic and non enzymatic antioxidant defense system. Reduced glutathione (GSH) is one of the important endogenous non-enzymatic antioxidants that provides sulphdryl (SH) group for direct scavenging reactions. GSH acts both as substrate in the scavenging reaction, catalyzed glutathione peroxidase (GPx) and as a scavenger of peroxyl radicals. ${ }^{25}$ Our data showed that GSH level was significantly lowered in AMI patients as compared to control and a negative correlation was observed between GSH and MDA levels in AMI patients ( $r=-0.515)$. The finding of the present study is in accordance with a number of studies. Erythrocyte GSH level has been found to be lowered significantly in AMI patients as compared to control. ${ }^{26-27}$ A negative correlation between GSH and MDA has been shown in both diabetic and non diabetic AMI patients. ${ }^{(27)}$ The decreased level of GSH and negative correlation of GSH and MDA levels in our study implies that glutathione system, is severely impaired in AMI patients. In our study, we found significantly low level of plasma vitamin E level in AMI patients compared with control. This indicates severe damage to antioxidant system which is unable to combat oxidative stress. Vitamin $\mathrm{E}$ is an important membrane constituent of cardiac muscle which haults lipid peroxidation by trapping the peroxyl radical and stabilizes lipid bilayer of cell membranes, where it interacts with phospholipases to reduce membrane rearrangements. ${ }^{20,} 28$ It may provide protection against ischaemic myocardial damage by eliminating pro-oxidants and scavenging free radicals. ${ }^{29}$ The low vitamin E level found in our study is in accordance with other studies. ${ }^{1,8}$, 27 Some studies showed that total antioxidant capacity (TAC) has been decreased in AMI patients. ${ }^{(13,23)}$ Decrease in the levels of GSH and vitamin $\mathrm{E}$ in our study may be due to increased turn over for preventing oxidative damage in these patients, suggesting an increased defense against oxidative damage in AMI patients.

In this study, on the $5^{\text {th }}$ day of regular treatment, we found significant decrease in plasma MDA level $(\mathrm{p}<0.001)$ in AMI patients, However the level did not reach to control value. We also found significant increase $(\mathrm{p}<0.001)$ in erythrocyte GSH and plasma vitamin E level in AMI patients on the $5^{\text {th }}$ day of regular treatment. LoPresti et al., ${ }^{22}$ found significant reduction of lipid peroxidation and NO metabolite concentration and increase of total antioxidant capacity (TAC) in young AMI patients after 12 months in comparison with initial stage. However each of parameters remained statistically different in comparison to normal controls. In our study on the $5^{\text {th }}$ day of treatment we found significant difference of MDA level as compared to control but the difference of erythrocyte GSH and plasma vitamin E level was not significant in comparison to control. It may be that TAC takes longer period to be restored.

Numbers of risk factors are associated with the pathogenesis of AMI. Increase in the concentration of plasma lipids is frequently observed in patients with AMI which contributes to the development of vascular disease. Cholesterol has been considered to be an important factor in the development of atherosclerosis. HDL-C provides protection against it by reverse transport of cholesterol. In our study, we found significant elevation of cholesterol and LDL-C levels in AMI patients with dyslipidemia or both dyslipidemia and DM as compared to control. There was significant decrease in HDL-C in the same group of patients. In patients with only DM, LDL-C level increased significantly. We found that the rate of lipid peroxidation was significantly high in AMI patients with or without risk factors as compared to control. MDA level was 
significantly different in patients with DM or both dyslipidemia and DM as compared to AMI patients with no risk factors. Plasma vitamin $\mathrm{E}$ and GSH levels decreased in AMI patients with or without risk factors. The decreased was more significant in AMI patients with risk factors than without risk factors. The finding of this study is in conformity with the previous observations. ${ }^{22}$ It can be predicted that oxidative stress in AMI patients is higher among the patients having more risk factors than the patients having no or less risk factors.

The findings of our study suggest that in AMI patients oxidative stress occurs as a result of an imbalance between oxidants and antioxidants. The magnitude of imbalance is greater in AMI patients with risk factors like dyslipidemia or diabetes mellitus. Amelioration of oxidative stress after regular treatment suggests that such an imbalance between oxidants and antioxidants may be involved in the pathogenesis of AMI.

\section{Limitation of the study:}

Due to the unavailability of the resources such as manpower, financial support and time limitation the study was done with small sample size.

\section{Reference:}

1. Bagatini MD, Martins CC, Battisti V, Gasparetto D, da Rosa CS, Spanevello RM, Ahmed M, Schmatz R, Schetinger MR, Morsch VM. Oxidative stress versus antioxidant defenses in patients with acute myocardial infarction. Heart Vessels. 2011; 26: 55-63.

2. Kasap S, Gonenc A, Sener DE, Hisar I. Serum cardiac markers in patients with acute myocardial infarction: Oxidative stress, $\mathrm{C}$-Reactive protein and $\mathrm{N}$-terminal probrain natriuretic peptide. J Clin Biochem Nutr. 2007; 41: 50-57.

3. Loeper J, Goy J, Rozenstajin L, Bedu O, Moisson P. Lipid peroxidation and protective enzymes during myocardial infarction. Clin Chim Acta. 1991; 15: 119-25.

4. Espat NJ and Nelton WS. Oxygen free radicals, oxidative stress, and antioxidants in critical illness. Support Line. 2000; 22: $11-20$.

5. Giordano FJ. Oxygen, oxidative stress, hypoxia, and heart failure. J Clin Invest. 2005; 115: 500-08.

6. Lazzarino G, Raatikainen P, Nuutinen M, Nissinen J, Tavazzi B, Di Pierro D, Giardina B, Peuhkurinen K. Myocardial release of malondialdehyde and purine compounds during coronary bypass surgery. Circulation. 1994; 90: 291-97.

7. Aznar J, Santos MT, Valles J, Sala J. Serum malondialdehydelike material (MDA-LM) in acute myocardial infarction. J Clin Pathol. 1983; 36: 712-15.

8. Muzáková V, Kandár R, Vojtísek P, Skalický J, Vanková R, Cegan A, Cervinková Z. Antioxidant vitamin levels and glutathione peroxidase activity during ischemia/reperfusion in myocardial infarction. Physiol Res. 2001; 50: 389-96.

9. Canbaz S, Duran E, Ege T, Sunar H, Cikirikcioglu M, Acipayam M. The effect of intracoronary administration of vitamin $\mathrm{E}$ on myocardial ischemia-reperfusion injury during coronary artery surgery. Thorac Cardiovasc Surg. 2003; 51: 57-61.
10. Cross CE, Halliwell B, Borish ET, Pryor WA, Ames BN, Saul RL, McCord JM, Harman D. Oxygen radicals and human disease. Ann Intern Med. 1987; 107: 526-45.

11. Ghiselli A, Serafini M, Natella F, Scaccini C. Total antioxidant capacity as a tool assesses redox status: critical view and experimental data. Free Radic Biol Med. 2000; 29: 1106-14.

12. Shaikh AK and Suryakar AN. Oxidative stress and antioxidant status before and after supplementation of A-Z anti-oxidant tablets in coronary artery disease. Biomed Res. 2009; 20: $136-40$.

13. Chen J and Mehta JL. Role of Oxidative stress in Coronary Heart disease. Indian Heart J. 2004; 56: 163-73.

14. Potenza MA, Gagliardi S, Nacci C, Carratu MR, Montagnani M. Endotheli Dysfunction in Diabetes: From Mechanisms to Therapeutic Targets. Curr Med Chem. 2009; 16: 94-112.

15. Vanhoutte PM. Endothelial dysfunction and vascular pathology. Bull Mem Acad R Med Belg. 2006; 161: 529-36.

16. Thygesen K, Alpert JS, White HD. Universal definition of myocardial infarction. Circulation. 2007; 116: 2634-53.

17. Yagi K. Lipid peroxides and human diseases. Chem Phys Lipids 1987; 45: 337-51.

18. Ellman GL.Tissue sulfhydryl groups. Arch Biochem Biophys. 1959; 82: 70-77.

19. Baker H and Frank O. Determination of serum á -tocoperol. In: Gokenlock AH, MeMurray JR, Mehauchian DM, eds. Varleys Practical Clinical Biochemistry. London. 1968: 902-03.

20. Frei B, Stocker R, Ames BN. Antioxidant defenses and lipid peroxidation in human blood plasma. Proc Natl Acad Sci. 1988; 85: 9748-52.

21. Surekha RH, Srikanth BB, Jharna P, Ramachandra RV, Dayasagar RV, Jyothy A. Oxidative stress and total anti oxidant status in myocardial infarction. Singapore Med J. 2007; 48: 137-42.

22. LoPresti R, Catania A, D’Amico T, Montana M, Caruso M, Caimi G. Oxidative stress in young subjects with acute myocardial infarction:Evaluation at the initial stage and after 12 months. Clin Appl Thromb Hemost. 2008; 14: 421-26.

23. Senthil S, Veerappan RM, Ramakrishna Rao M, Pugalendi KV. Oxidative stress and antioxidants in patients with cardiogenic shock complicating acute myocardial infarction. Clin Chim Acta. 2004; 348:131-37.

24. Esterbauer H, Shauer RJ, Zollner H. Chemistry and biochemistry of 4-hydroxynonenal malonaldehyde and related aldehydes. Free Radic Biol Med. 1991; 11:28-81.

25. Myers ML, Bolli R, Lekich RF, Hartley CJ, Roberts R. Enhancement of recovery of myocardial function by oxygen free radical scavengers after reversible regional ischemia. Circulation. 1985; 72: 915-21.

26. Shinde S, Kumar P, Patil N. Decreased levels of erythrocyte glutathione in patient with myocardial infarction. Int J Alt Med. 2005, 2: 1-8.

27. Patil N, Chavan V, Karnik ND. Antioxidant status in patients with acute myocardial infarction. Ind J Clin Biochem. 2007; 22: 45-51.

28. Evans $\mathrm{P}$ and Halliwell B. Micronutrients: oxidant/antioxidant status. Br J Nutr. 2001; 85: 67-74.

29. Bandyopadhyay D, Chattopadhyay A, Ghosh G, Datta AG. Oxidative stress-induced ischemic heart disease: protection by antioxidants. Curr Med Chem. 2004; 11: 369-87. 